\title{
METHODS FOR ESTIMATING PASTURE DRY MATTER ON DAIRY FARMS IN NORTHLAND
}

G.J. PIGGOT

Agricultural Research Division, MAF, Whangarei

Abstract

Pasture dry matter (DM) estimates are used by dairy farmers and their advisers for feed planning principally during April to September. The three primary estimates required are: average farm cover, pre-grazing herbage on offer, and post-grazing residue. Average farm cover can be approximated by averaging paddocks with the highest and lowest DM. Various 'short-cut' methods (pasture height weighted disc pasture 'probe') were evaluted during 1984 and have provided calibration equntions for 'feed budgeting' of pre-calving feed. Such equations could be used for day-to-day feeding calculations during autumn to spring provided their limitations are recognised

Keywords: Pasture dry matter, herbage mass, dairy farm, feed budgeting, visual estimate, pasture height, weighted disc, pasture probe.

\section{INTRODUCTION}

Grazing management and livestock feeding requirements are increasingly being described in terms of pasture dry matter (DM), total DM, or herbage mass as DM (Parker 1973, Hodgson 1979). Farm management techniques such as 'feed budgeting' (Scott et al. 1979) or 'pasture allocation' (Milligan and Smith 1984) are based on kg of pasture DM either as intake, pasture offered, or residue following grazing. Clear, well documented, and practical guidelines on how farmers and their advisers should estimate pasture DM, and how they should collect accurate paddock and farm estimates, are not available. The purpose of this paper is to describe current research which attempts to provide such guidelines, especially for Northland dairy farms.

To date, farmers and advisers have been expected to recognise pasture DM, either from occasional calibration or from verification based on animal responses to preselected DM feeding levels. Scientific objections to such methods relate to the human variation in day-to-day visual estimation and to the need for numerous, careful, and independent assessments within a paddock to provide an accurate paddock estimate (Parker 1973, Baars and Dyson 1981, Stockdale 1984, Piggot and Morgan 1985). The inevitable conclusion is that the correct application of visual estimation methods (i.e. using many within-paddock estimates and regular calibration cutting) is impractical in commercial farming. Such a conclusion dictates a requirement for 'short-cut' methods of calibration and ways of avoiding the time-consuming effort of accurately estimating every paddock on the farm and calculating the total farm DM. This paper proposes some practical solutions to these problems.

\section{METHODS}

Two separate trial series were conducted.

\section{Farm Cover Estimation}

The pasture DM for every paddock was assessed on each of 10 dairy farms in mid and lower Northland monthly during July 1982 to September 1983. There were at least 35 paddocks on each farm. The paddock visual estimate was the mean of 20-30 independent visual estimates along a transect representative of the whole paddock. Calibration of estimates (against 5 cut quadrats) was conducted at each farm visit by sampling in one 'representative' paddock. 


\section{Calibration Methods}

Six dairy farms on 'clay' soils (three in Whangarei and three in the Ruawai-Dargaville districts) with ryegrass-white clover pastures were visited monthly from May to October 1984 except during August, though not during rainy weather. A paddock ready for grazing and a paddock recently grazed were selected and $10 \times 0.25 \mathrm{~m}^{2}$ quadrats were placed representing the range of standing DM. For each quadrat the following were conducted:

1. Pasture height: Measured by placing a ruler at ground level and assessing the average height of herbage in the quadrat.

2. Disc reading: One measurement with an Ellinbank weighted disc meter.

3. Correct probe reading: Four points in the quadrat were measured with a 'pasture probe' capacitance meter and were corrected against an air reading taken prior to measuring each quadrat.

The quadrat was then cut with hand shears as close as possible to ground level without collecting any soil (called here 'grazable DM'). Within the quadrat, after hand-cutting, a $0.1 \mathrm{~m}^{2}$ quadrat was placed and cut by a shearing handpiece. This sample was harvested at the level of the ryegrass crowns which was often below ground level (called here 'stubble DM'). Therefore total DM = grazable DM + stubble DM. The grazable DM sample was not washed prior to drying but the stubble DM sample was. The 'stubble DM' samples were cut by the same operator, while a variety of operators cut the 'grazable DM' samples.

\section{RESULTS AND DISCUSSION}

\section{Farm Cover Estimation}

The per-paddock visual estimates were corrected using the linear regression equation from the calibration cuts for all paddocks from the 45 visits when hay or silage paddocks were not closed. The five highest and five lowest yielding paddocks (as $\mathrm{kg} \mathrm{DM} / \mathrm{ha}$ ) were extracted from the data for each farm visit together with the correctly-calculated farm cover estimate; i.e. calculated from aggregates of the total DM from each paddock divided by the total grassed area per farm. The mean of groups of the highest and lowest paddocks (Table 1) were within approximately $100 \mathrm{~kg} \mathrm{DM} / \mathrm{ha}$ of the correctly-calculated farm cover, and the more pairs of highest and lowest yielding paddocks grouped for averaging, the closer to the average farm cover was the mean. (The term 'difference' is the absolute difference whether positive or negative.)

Therefore, farm cover can be calculated as the average of highest and lowest yielding paddocks with a precision similar to that of the correct farm cover estimate, which is about 200kg DM/ha (Piggot and Morgan 1985). This 'short-cut' avoids walking the entire farm, preparation of accurate farm maps of grassed hectares, and cumbersome total DM calculations. Since pre- and post-grazing paddocks are usually

TABLE 1: The Difference (Kg DM/ha) Between Average Farm Cover and the Mean of Highest and Lowest Yielding Paddocks on the Farm for 45 Farm Visits.

\begin{tabular}{cccc}
\hline & Mean & difference & $\begin{array}{c}\text { Standard } \\
\text { deviation of the } \\
\text { difference }\end{array}$ \\
\hline Mean of highest and lowest paddocks & 119 & 95 \\
Mean of 2 highest and 2 lowest paddocks & 104 & 88 \\
3 & 3 & 85 & 83 \\
4 & 4 & 75 & 80 \\
5 & 5 & 65 & 77 \\
\hline
\end{tabular}


the highest and lowest yielding, such DM estimates can also be used to assess animal feeding regimes.

\section{Calibration Methods}

The results from the first season of a long term study, while preliminary, demon strate issues related to the estimation of pasture DM using 'short-cut' methods,

Firstly, 'stubble DM' values varied widely between farms. An illustration is the monthly mean and range of values from the average of the 20 quadrats cut on each farm (Table 2).

These results cast doubt on the validity of offering universal grazing management or livestock feeding recommendations based on pre-grazing total DM, residual DM, or herbage allowance (Scott et of. 1979, Smith and Milligan 1984), if such recommendations must be measured as total DM. As stubble DM is effectively below grazing height, management concepts based on 'grazable DM' rather than total DM may be more relevant to farmers.

TABLE 2: Stubble DM (Kg/ha) Means and Ranges for Months, Samples in Two Paddocks on Six Farms.

\begin{tabular}{lcc}
\hline & mean DM & Range \\
\hline Month: & & \\
May & 1530 & $1040-1980$ \\
June & 1440 & $860-2470$ \\
July & 1340 & $920-1940$ \\
September & 1100 & $800-1800$ \\
October & 1210 & $920-1520$ \\
\hline
\end{tabular}

The 'short-cut' methods predicted either total DM or grazable DM with similar precision as indicated by the correlation coefficients of the regression relationships (Table 3). Incidentally, these results suggest that there is virtually no difference in precision between a ruler, a disc, or a probe.

Pasture height is the cheapest and least demanding of the 'short-cut' methods. Using pasture height as an example, the parameters of the average calibration equations over the six farms are displayed in Table 4. (The equivalent tables to Table 4 for the disc and the probe are available on request.)

These data, when allied with similar analyses of disc and probe data, indicate: a trend for regression line slope to be a minimum in July, a distinct variation between farms in the slope and intercept of the regression line as indicated from the SE, and a difference between pre- and post-grazing paddocks.

Clearly, a single calibration equation could not provide correct estimates of total or grazable DM from May to October for all farms. One solution (to provide a single calibration equation) is to recognise that the primary requirement for DM estimates during this period on dairy farms is to assist planning for enough feed for calving which occurs in July or early August. Based on Table 4, and equivalent disc and probe data, such equations would be:

Total $\mathrm{DM}=160 \mathrm{x}$ pasture height in $\mathrm{cm}+1200$ for pre-grazing pasture

Total $\mathrm{DM}=160 \mathrm{x}$ pasture height in $\mathrm{cm}+800$ for post-grazing pasture

The slope of calibration equations for the disc and probe CMR readings are 100 and 9 respectively rather than 160 . These equations essentially estimate differences in 'grazable DM' and add on a stubble value to provide total DM as $\mathrm{kg} \mathrm{DM} / \mathrm{ha}$. These equations are therefore arbitrary and averages of only six farms in one year, for one period of the year. Their validity will be checked in due course, on a wide sample of dairy farms. 
TABLE 3: The Error in the Linear Calibration Relationship Between 'Short-Cut' Methods and Total or Grazable DM for Samplings from May to October 1984.

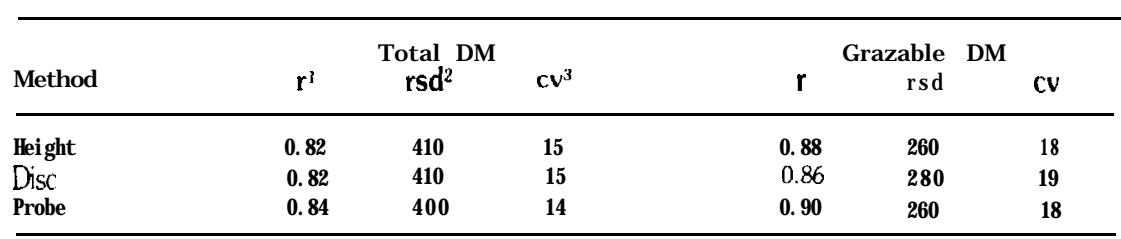

1 Correlation coeffici ent

2 Residual variability of the regressi on equation as $\mathrm{kg} \mathrm{DM} / \mathrm{ha}$

3 Coefficient of vari ation as $\%$

TABLE 4: Parameters of the Average Calibration Equation for Pasture Height, to Provide Total DM or Grazable DM as Kg DM/ha, Meaned Over Six Farms.

\begin{tabular}{|c|c|c|c|c|c|c|c|c|}
\hline \multirow[b]{3}{*}{ Month } & \multicolumn{4}{|c|}{ Total DM } & \multirow{2}{*}{\multicolumn{2}{|c|}{$\begin{array}{l}\text { Grazable } \\
\text { Pre-grazing }\end{array}$}} & \multirow{2}{*}{\multicolumn{2}{|c|}{$\begin{array}{l}\text { DM } \\
\text { Post-grazing }\end{array}$}} \\
\hline & \multicolumn{2}{|c|}{ Pre-grazing } & \multicolumn{2}{|c|}{ Post-grazing } & & & & \\
\hline & $\mathbf{a}^{1}$ & $\mathrm{~b}^{2}$ & a & b & a & b & a & $\mathbf{b}$ \\
\hline May & 1300 & 250 & 1000 & 280 & 0 & 210 & -100 & 210 \\
\hline June & 1300 & 170 & 900 & 240 & 300 & 130 & -200 & 160 \\
\hline July & 1500 & 150 & 800 & 270 & 200 & 150 & -300 & 190 \\
\hline Sept. & 1300 & 190 & MO & 240 & 300 & 180 & -100 & 230 \\
\hline ot. & 1900 & 190 & 800 & 320 & 400 & 200 & 0 & 250 \\
\hline SEM & 300 & 20 & 200 & 40 & 200 & 20 & .100 & 30 \\
\hline
\end{tabular}

\section{Intercept \\ ? Sl ope of regression}

The appeal of single equations lies in their simplicity and also because the use of 'short-cut' methods is already common practice, despite the lack of any documented basis. A compromise must be reached between scientific or statistical objections to 'short-cuts' and the demands of dairy farmers, The use of such equations for feed budgeting must recognise that the earlier or later from July the measurement is taken, the greater will these equations underestimate 'grazable DM', and the estimate of 'total DM' for any farm is abstract since stubble DM is an assumed value.

\section{CONCLUSION}

Investigations of 'short-cut' methods of assessing pasture DM from autumn to spring on dairy farms in Northland during 1984 suggest that paddock estimates can be gained by taking numerous, independent estimates of pasture height (or disc or probe readings) and calibrating them against a single equation depending on whether pre-grazing or post-grazing pasture is being assessed. An adjustment would be needed for estimates taken earlier or later than July if using the equations presented here. For feed budgeting, the pasture height measurement could be maintained throughout the period ignoring changes in DM. For animal feeding, estimates from 'short-cut' equations should be inflated by 200 'sg DM/ha for each month earlier or later than July the measurement is taken. A farm cover estimate can be gained by averaging the estimates from paired groups of the highest and lowest yielding paddocks. 


\section{Acknowledgments}

The farmers who co-operated are thanked and the technical assistance of colleagues, particularly H.M. Morgan and W.B. McMeikan, and the biometrical advice from J.E. Waller, is gratefully acknowledged.

\section{References}

Baars, J.A.; Dyson, C.B. 1981. N.Z. J exp. Agric. 9: 157-160

Hodgson, J. 1979. Gross Forage Sci 34: 11-18.

Milligan, K.E.; Smith, M.E. 1984. N.Z. Agric. Sci. 18 (3): 153-156

Parker, O.F. 1973. Proc. N.Z. Grassld. Ass. 35: 127-134

Piggot, G.J.; Morgan, H.M 1985. N.Z. J exp. Agri c. 13: In press

Scott, J.D.J.; Lamont, N.; Smeaton, D.C.; Hudson, S.J. 1979. Sheep and cattle nutrition. Aqric Rrs Div., MAF. $151 \mathrm{pp}$.

Stockdale, C.R. 1984. Aust J. exp. Agric. anim. Husb. 24: 300-304 